\title{
FENOMENOLOGIA HEIDEGGERIANA E SUA POSSIBILIDADE NA CONSTRUÇÃO DE ESTUDOS DE ENFERMAGEM
}

\author{
Heideggerian Phenomenology and its possibility in \\ the nursing studies constructions \\ Fenomenologia Heideggeriana y su posibilidad \\ en la construcción de estudios de enfermería
}

CaudeteFerreradeSouzaMbrterro

SilvanaSartiago daRocha

EizabetePimentaAraújoPaz

Ivis EniliadeOiveraSaza

\section{Resumo}

Esteestudbapresenta umareflexão sobre o métodb fenomendógico heideggeriano esuapossibilidadena pesquisa emEnfermagem Otrabalho rrostraquea Erfermagempredsa compreender edar sentido às suas açoes deforma mais autêntica eaponta a fenomenologia como a possibilidade de permitir queos profissionais setomemmais atentos ereflexivos sobrea realidade o omodo deser deoutros.

Palauras-dave Fenomenologia PesqisaemEremzgem Ciidar.

\begin{abstract}
Resumen

Thisstudypresentsareflectionabatthephenomenologicd Este estudio presenta una reflevión sobre ed método Heideggerianmethodandits possibilityintheresearchin fenomenológico de Heidegger y su posibilidad en la nursing Theworkmakes dearthenecessitythat thenursing investigacón en enfermería 8 trabajo mestra que la needs to understand and to giveseneto its actions ona enfemería necesitacomprender ydar sertidbasus acciones

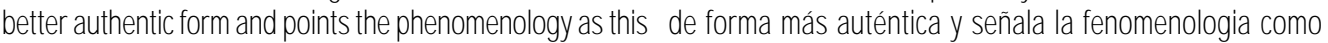
makes possible capadle to allow that the professionals posibilidaddepemitirquelosprofesiondesseenniás dertos becomemoreattentiveandreflectiveabout thereelityand yreflexios sobrelarealidadylamaneradeser dectros. the way of being of others.
\end{abstract}

Keyords

Phenomendogy. ReseerchinNursing Totakecareof.

\section{Palabasdae}

Fenomenologia In estigacionesenErermería. Giidado. 
INTRODUÇÃO

Impulsionadas pelo desejo de ampliar disaussões acerca da fenomenologia e sua contribuição como trajetónia retodblógica nos estudos emEnfermagem, nos propomos levantar algumas reflexões sobre esta corrente filosófica e o legado de Mertin Heidegger no que se refere ao conhedirento do homemcomo ser de possibilidades. Opropósito deste artigo baseiase, pois, em abordar alguns conceitos de Heidegger, descritos em seu livro Ser e Tempo, que possam despertar e subsidiar metodologicanente a busca da compreensão dos fenômenos ligados à nossa prática

Assimé que quando iniciamos umestudb, o nétodo se apresenta como um desafio. A escolha dele dependerá de vários fatores, como a natureza do objeto, dos recursos materiais disponíveis, nível de abrangência do estudo e, prinapalmente, da inspiração filosófica do pesquisador ${ }^{1}$. A fenomenologia como proposta metodblógica apresenta-se como um dos caninhos no campo da saúde, sendb una possibilidade de compreensão do ser humano?. Cada nétodo, a seu nodb e a seu tempo, juntanente comos pressupostos epistemblógicos, oferece caminho a ser seguido que dependerá tambémcla visão de mendo do pesquisadbr ${ }^{3}$.

A pesquisa na área da saúde e, portanto, na Effermagemsurgiu à luz do modlo bionédico, voltadb para causas e efétos da doença. A pessoa doente só recenterente vemsendo foco de atenção para busca dos significados e vivências do que é ser doente. Entendermos que a fenomenologia se apresenta com alternativa para compreender estas preoaupações que energemdo nosso cotidiano. A fenomendogia permite que a Enfernagem tenha uma compreensão da doença, que representa una modalidade do seu ser emsua forma de viver ${ }^{4}$. Permite também que o mundo, as relações humanas e o aidar possamser olhados de modo diferente.

\section{FENOMENOLOGIA - UMA CIÊNCIA EIDÉTICA}

A fenomendogia é ummovimento filosófico nascido no coneço do séalo XX comEdmendo Hussel, que, ao confrontar o psicologisno vigente, tentou explicar atos e pensamentos humanos e, assim responder a um prodlen a do pensanerto dentífico da época, quese referia an questionamento das dues formas de combedimento: 0 empinismo, no qual o mundo era considerado uma náquira impessod, e o raciondisto, que tenda a exdur o mundo deixandb apenas una visão reflevivé.

Hissel, a pertir do conceito de intencionalidade de Franz Brentano, filósofo e sacerdote católico alenão, do qual fai aluno, desenvolve sua filosofia da fenomendogia e diz que a diência que pretende ser objetiva tem intencionalidade, e o resultado sempre é una realidade dgjetiva da qual se retircu a importânaia humara Assim, a fenomenologia exalta a interpretação do mundo que surge intencionalmente à consciência, enfatizando a experiênaia pura do sujeito ${ }^{6}$.

A base da fenomenologia husserliana é a intencionalidade da consciêndia que está direcionada pera algo. Oque significa que rão há pura consciênaia, separada do mundo, mas que toda consciência tende para o mundo, toda consciência é consciência de alguma coisa7. Husserl mostra a importância de colocar a nossa própria experiência da realidade na forma de ver os fenômenos.

Ofenômeno, ou seja, o que se mostra a si nesmo tal como é, se apresenta no método fenomenológico como o objeto da investigação e como principal instrumento de conhedimento. Este rétodo adbta a intuição, já que de acordo comHusserl, as essêndas são dadas intuitivamente O fenômeno, para Husserl, não é necessariamente coisas, mas qualquer fato, seja de natureza psicológica ou física, desde que seja doservado e contemplado por uma consciêndia:

Husserl teve seguidores, e um deles foi Martim Heidegger, filósofo alemão, professor e reitor de una das mais conceituadas universidade de Freiburg, aja dora nais importante, Ser e Terno (1927), apresenta o hanem como expressão ontológica, disatindo essa facticidade do existir do ser. Oser ocorre no termpo, e o fato de existimos no tempo nos leva a constate midanças, nos deparando comnoves possibilidades e convivendo com das à medida que continuanos existindb no ternpo.

A expressão fenomenologia diz deixai e fazer ver por si mestro aquilo gue se rostra, tal como se mostra a partir de si mesmo. E complementa afimando que é este sertido formal da pesquisa que traz o nome de fenomenologia. Entretanto, o filósofo vai mais além de restro se questiona usandb a interrogação o que é que se deve 'deixar e fazer ver'? E a esse questionamento reflexivo e profundo, ele próprio responde, afimando:

Justo o não se mostra diretamente e na maioria das vezes e simse mantémvelado frente ao que se mostra diretamente e na maionia das vezes, mas ao mesmo tempo pertence essencialmente ao que se mostra diretamente e ra naionia das vezes a ponte de constitur o seu sertido e fundanento ${ }^{0}$.

Ofilósofo, comseu pensamento arrojado, analisou de forma aútica o mundb contemporâneo, o tecricismo e o sertidb db ser. Para ele, a fenomendogia possibilita umcaminhar para o ser, pois o ser é aquilo que se 
oculta naquilo que se manifesta e constitui o fundarmento de tudo o que se revela

Na concepção heideggeriana, não se separa o homem do mundo, pois isso denotaria a separação entre sujeito e objeto. Para o filósofo, o mndo não se configura umespaço topográfico, mas reflete e compreende as várias formas de se relacionar, como viver e cono pode se comportar.

Hejdegger indica que as coisas só acontecem, só se nostram só se anunaamna presença do ser-á, o qual drande Dasein requilo que separa o horemde atros entes, e que esta presença é una condção de mundb, é sempre una abertura de mondb. Desein está aberto a possibilidades de criar seus próprios sertidos para a vida, a fim de alcançar sua existência autêtica ${ }^{10}$.

Aexpressão existêndia para Haidegger não significa realidade ou aquilo que está no mndb, mæs existênda, da forma comb étratada em Ser e Ternpo, vemdb verbo ek-sistere, ek-esistênda e se compreende conr aquilo que na verdade energe, desvela. Aexsistênia, para o filósofo, se constitu detrês aspectos - a faticidade, cono o estar-á, lançadb mo mondo, semattemetives de escolhes; a

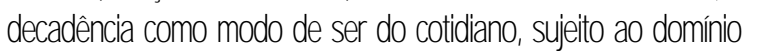
do impessod e caraderizado palo falatónio, a riosidadee antigï̈dadé e a transcendênda, umnodb de projetar-se para alémdesi edescodair o próprio sertido ${ }^{10}$.

Como então buscar o sentido do ser utilizando a fenomenologia? Essa resposta situa-se no campo da pesquisa qualitativa, pois a fenomenologia como método de estudo é eminentemente uma busca qualitativa, e seu atributo maior fundamenta-se na linguagem pois é por meio do disarso que se toma realidade aquilo que faz sertidb para o sujeito, e esse sentido se manifesta mediante a descrição.

Por ser o discurso umexistendial originário da abertura, ele é constitúdo pelo ser-no-mendb e, como tal, possui a essêndia espedificarrente mundana:

A linguagemé o pronundiamento do disaurso. Como ente intramndano, essa totalidade de palavras, emque como tal o disarso possui seu próprio ser "mundano", pode ser encontrada à maneira de ummanual. Nesse caso, a linguagem pode ser estilhaçada em coisa-palavra simplesmente dada. Existencialmente, o discurso é linguagem porque aquele ente, aja abertura se articula em significações, possui o modo de serlançado-no-mundo, dependente de mundo 10.

Ofilósofo mostra que a abertura do ser-á é que Ihe permite essa expressão lingǘstica e que o disarso é uma instânda ontológica que pode ser manifestada emoiversas línguas, compartilhada comatros, e que permite transmitir vivêndias, partilhar sentidos e trazer informações do próprio interior do sujeto. È, pois, com base nessa abertura, que se induemas emroções, vida afetiva, lazer, trabalho, crenças e outros aspectos fundamentais da existência humana Esses são termas de interesse da fenomenologia.

O disaurso tem seus vários constituintes. El se marifesta por meio da linguagem, que pode ser escrita, falada, gestual, ou mesmo a linguagemsilenciada. Estes constituintes podemse partilhar no ser-como tema proposto, e para que haja a compreensão, é necessária a esata ouvir o que o ser busca revelar. A escuta atentiva do discurso é o estar ouvindo compartilhando o ver, e é aqui que a intencionalidade da consciência possibilita sua direcionalidade ${ }^{10}$. Portanto, para o pesquisador compreender o significado ou desvelar o sertido contido no disarso, há que ter umgrande envolvimento da subjetividade, e é esta que garante a objetividade

O primeiro passo do método é o discurso. O pesquisador pergunta ao sujeito e este responde significando o perguntado. No passo seguinte, o pesquisador deve dedicar-se ao material descrito a fim de buscar o significado das vivências que entergemdo real vivido. Esse significado Heidegger nomeia de compreensão vaga e rediana ${ }^{10}$.

CONSIDERAÇÕES FNAIS

Afenonendogia rẽo presainde de pressupostos teóricos e de un a fómela nígda de lusca da vercade Ba tempor dgjetivo ir-àcoisarmesta, ou seja, reveála ta como da se nostra se narifesta seapresertae, desta naneira constrá una verdade AEffermagem una dênda que tempor dgetios o aider do a tro encontra ra fencmendogia esse canitho deinestigar fenônenos que, a priori, não são fácés deconpreensãa Oaider do atro reda factes tãosinglares, tão subjetives e tão autêticas que acreditanos ser a

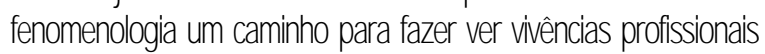
easpetos do diettequese encortrampresos palas distrações do cotidano e que, commerte, impedamque este possa tomar posiçoes, interagir e patiajpar da vica emcome ricade de forma autêtica

Esta reflexão nos mostra que a enfermagemprecisa compreender e dar sertido às sues ações de forma nais atêtica ea pesquisa uilizandb a fenconendogia possibilita aos profissionais dar sertiob às sues vinênias e atividades profissionas, torrandbse profissionais mis dertos e reflexios solre a realidade e o modb deser de a tros.

Os estudos que pretendem corhecer comro o homem encontra se vivendb alguma situeção ou significando sua relação com o mudo devem buscar se apoiar nos conceitos heideggerianos. 


\section{Referências}

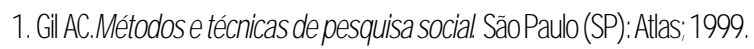

2 MbrenoRLR JorgeMEB, GarciaMP. Fenomenologia fenômeno situadb: opcãom toddógica parain estigar o humæno naáreada saúde EscAmaNeryRevErferm2004dez; 8(3):348-353.

3. Bruns MAT. Reflevões acercadb "fazze" medodbógico. In Castro DPP, AzarP, PicanoJD, Josgrilberg RS, argarizadbres. Fenomendogia eanálisedbexistir. UniversidadeM MtodstadeSãoPalo(SãoBemardo do Campo): Sodraphe, 2000.

4. Capalbo C Pós-modemidade razãosensíve, fenomenologiaea enfermagem PevClenSáde1997jan/dez; 16(1-2): 32-47.

5. Stevensonj. Onais completogiasolrefilosofia Traduçãodelvo Kontuski. SãoPaulo(SP): Mandarim,2002.

6. ColtroA Afenomenologia: umenfoquemetoddógico pera além da modemidade. CadernodePesquisaemAdhinistração.2000 jan/fev/mar, 1(11): 37-45.

7. BuenoRA Fenomendogia avdtaàs coisas mesma. In Peixoto A), orgarizadbr. Interaçōesertrefenomendogiadedração.Campines (\$): Aínear 2003.

8. Barreto JAE, Moreira RVO. Husserl e a ática da razão. In: Barreto JAE, Mbreira RVO, organizadores. Adedisãodesatumo: filosofia, teorias deerfermagemeaidadbdb humano.Fortdeza(Ф): CasadejosédeAlenca/ProgramaEdtoria; 2000.

9. Stevenson J. Onais completo guia sobrefilosofia SãoPaul(S): Mendarim 2002.

10. Hadkegger MSeretempo_Patel. Trad çãodeMáriaSáCavdcarteSchubadk 12ª̈ed SãoPaulo(S):Vozes; 2002.

\section{Sobre os Autores}

\section{CaudteFericiadeSouraMulto}

Professorada LhiversidadeFederal do Piaú.

DoutoraemErermagempedaEANVIPIJ.

\section{StramsatiagodaPoda}

Professorada L tiversidadeFederd do Piaú. DoutorandaemE EfertagemmaEAVUFI.

\section{ErabelePinemaAajoPaz}

Professorae DoutoraenEffermagemnaEAVUFI.

\section{MisEm adeOineiaSoura}

ProfessoraTtilare DatoraemErfermagemmaEAVUPI. 